\title{
PERFORMANCE OF STEEL FIBER REINFORCED CONCRETE - COMPARABILITY OF TESTS ACCORDING TO DAFSTB-GUIDELINE "STAHLFASERBETON" AND EN 14651
}

\author{
Steffen Anders*, Melanie Schovenberg
}

\author{
Institute of Structural Engineering, Bergische Universität Wuppertal, Pauluskirchstr. 11, 42285, Wuppertal, \\ Germany \\ * corresponding author: baustoff@uni-wuppertal.de
}

\begin{abstract}
For the determination of the performance of steel-fiber reinforced concrete (SFRC), the post-peak flexural strengths are used. In different national and European standards, different test-setups are defined, resulting in double efforts for testing for the manufacturers. In addition, the German national guideline "Stahlfaserbeton (DAfStb)" on SFRC is well established European-wide, but the test standard is specifically national, demanding a four-point-bending tests using unnotched beams. Contrarily, the European standard EN 14651 as well as the Model Code 2010 [1] demand three-point bending tests using notched specimens. Applying the national guideline is obligatory in Germany for structural use of SFRC. Therefore, it is essential to standardize the performance evaluation of SFRC based on commonly applied international guidelines. In the following, an approach is presented especially dealing with the problem of random occurrence of cracks in the four-point-bending tests. It is shown, that neglecting the point of crack can systematically under-estimate the performance of SFRC especially at deformations.
\end{abstract}

KEYWORDS: steel-fiber reinforced concrete, performance classes, post-peak flexural strength.

\section{INTRODUCTION}

In order to get permission to distribute and sell steelfibers in Europe, a CE-certificate is obligatory. Therefore, it is necessary to determine the performance of the steel-fibers in concrete, depending on the type of steel fibers as well as the fiber contents. In this case, the EN 14651 [2] is the relevant standard, demanding a test using third-point loading on notched specimens. In order to get the permission to sell steel-fiber reinforced concrete e.g. as ready mixed concrete the performance of SFRC has to be evaluated according to the German national guideline "Stahlfaserbeton (DAfStb)" 3. This guideline demands tests on unnotched specimens in a 4-point bending set-up. In both guidelines, performance of SFRC is measured in terms of post-peak flexural strengths.

Seen from the mechanical point of view the evaluation of post-peak flexural strengths is a fracture mechanical problem, demanding determination of strengths and load bearing capacities directly in the crack. This precondition is fulfilled only by EN 14651 but not by the German guideline, because the crack can occur anywhere in the mid third of the beam due to the four-point-loading scheme.

In order to overcome the problem of mechanical incorrectness as well as achieving international standardization, establishing a connection between the two test methods would be advantageous to facilitate the conversion of results from one method to another. One important aspect in this context is to include the point of crack into the evaluation according to the
Guideline "Stahlfaserbeton". This aspect will be dealt with in the following.

\section{Test METHOdS AND EVALUATION OF POST-PEAK FLEXURAL STRENGTHS}

The most important difference between the national guideline "Stahlfaserbeton (DAfStb)" and the European standard EN 14651 is the test set-up as shown in Fig. 1. In the four-point loading test, which is demanded by the guideline "Stahlfaserbeton (DAfStb)", the crack should occur randomly in the mid third between the two loads due to lacking of a notch. The deflection of the beam is measured using transducers at mid-span. As described, due to this distance the testing method is not consistent from a fracture mechanical point of view. The method given in EN 14651 uses a notched beam and just one load exactly above the notch at mid-span. Thus, deflection and cracking are in-line.

The evaluation of the post-peak flexural strength in the guideline "Stahlfaserbeton (DAfStb)" uses the mid-span deflection $\delta$. In this guideline, the post-peak flexural strength is calculated from the load at two defined deflections of $\delta=0.5 \mathrm{~mm}$ and $\delta=3.5 \mathrm{~mm}$ at mid-span (see Fig. 2-up). Seen from point of view of fracture mechanics, the deflection at the point of crack is always higher than the deflection at mid-span, resulting in a systematic underestimation of the postpeak flexural strength, provided a strain softening behavior of the steel-fiber reinforced concrete. 

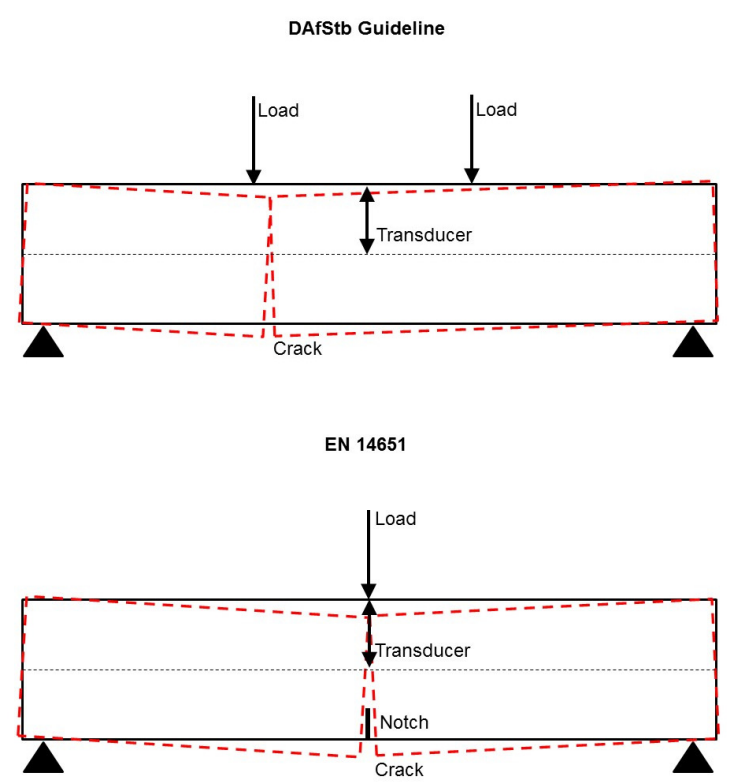

Figure 1. Comparison of test set-ups

On the other hand, the EN 14651 standard uses the Crack Mouth Opening Displacement (CMOD) being directly correlated to the mid-span deflection 4 . To specify the post-peak flexural behavior, strength values at four different points are defined in terms of CMOD (see Fig. 2-down). The deflection at $\delta=$ $0.47 \mathrm{~mm}$ at CMOD1 correlates well to the German guideline. CMOD4 at a deflection of $\delta=3.02 \mathrm{~mm}$ shows a difference of about $0.5 \mathrm{~mm}$ for the evaluation point. Additionally, the cross-sections differs either, for the notch reduces the height of the cross section (both beams are produced with a cross-section of $150 \times 150 \mathrm{~mm})$. The approach of the EN 14651 is consistent with respect to fracture mechanics, because the deflection is measured directly in the cracked crosssection.

The shown differences in testing and calculating make it nearly impossible to compare the results of the guidelines. A special problem being the random cracking with German test set-up.

\section{Calculation approach}

To adjust the results taken during the tests according to the guideline "Stahlfaserbeton (DAfStb)" the point of the first crack has to be measured. If this is done the deformations measured at mid-span, can be transferred to the cracked cross-section by simply using theorem of intersecting lines applied on the larger part of the beam, assuming both parts of beam are not deformed themselves. Fig. 3 shows that the deflection in the cracked cross-section is always larger than deflection at mid-span.

The consideration of the point of the crack results in an increased stretching of the force-deflection curve. The correction of the curve increases with an increasing deflection during the test as well as with an in-
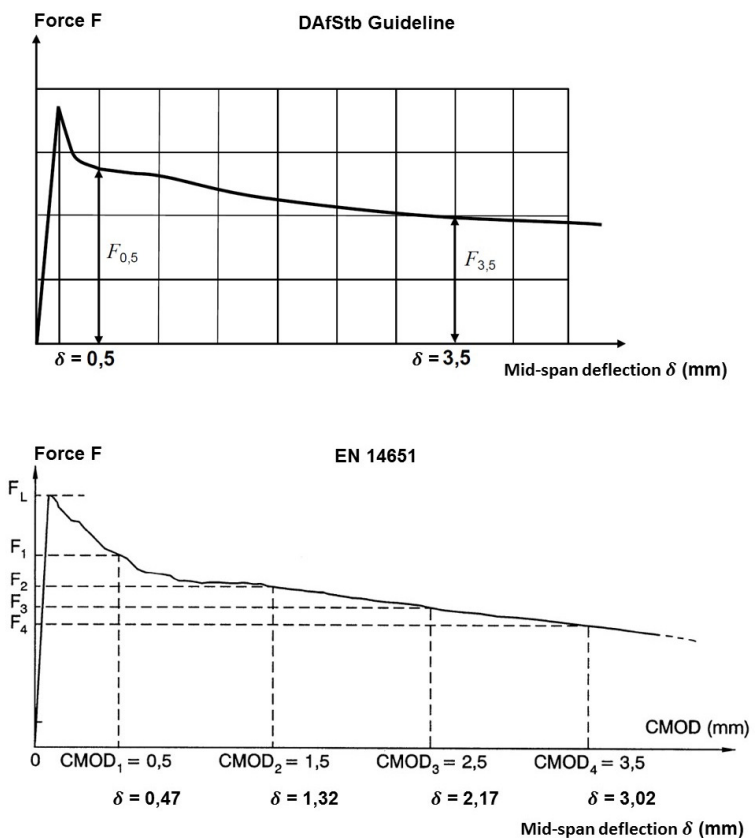

FiguRE 2. Evaluation of post-peak flexural strengths at different points. Up DAfStb-Guideline "Stahlfaserbeton", down EN 14651

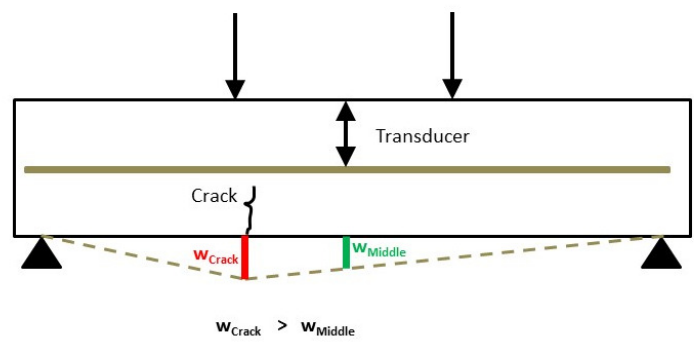

Figure 3. Calculation approach for taking the point of crack into account using the theorem of intersecting lines

creasing distance of the crack from the middle of the beam. In Fig. 4 the increased stretching can be easily seen especially at higher deflections.

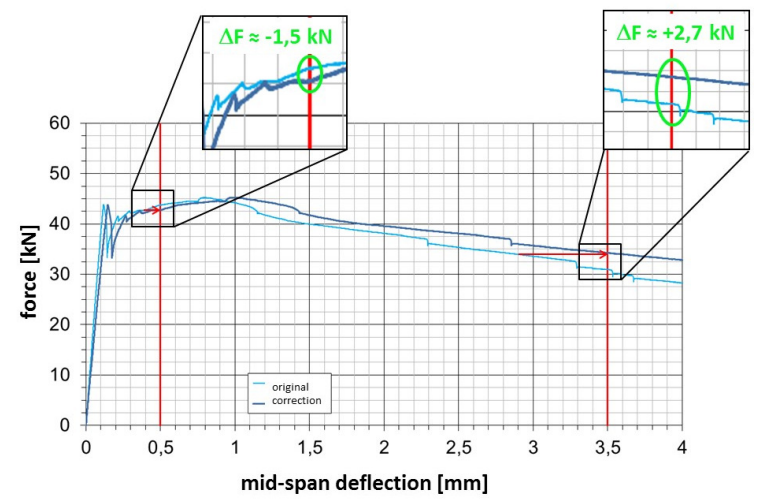

FiguRE 4. Change of mid-span deflection in case of strain hardening material at low deflections and strain softening at high deflections 
Depending on the effectiveness of the fibers (and on the fiber content), generally two different material behaviors are distinguished. Either the material is strain hardening, meaning that the transferred load increases with an increasing deflection or the material is strain softening, showing decreasing transferable loads with increasing deflections. In Fig. 4 the postpeak flexural strength for low deflections of about $\delta=0.5 \mathrm{~mm}$ shows strain hardening. In case of strain softening, as can be seen at a deflection higher than about $1 \mathrm{~mm}$ a correction of the load-deflection curve leads to increasing post-peak flexural strengths.

\section{Results And Discussion}

After measuring the point of crack of about 360 fourpoint bending tests, the resulting distribution of the point of crack is given in Fig. 5 The displayed distance of the crack from mid-span does not differ whether the crack occurred left or right from the mid of the beam. Assuming a perfectly homogeneous concrete, the crack should theoretically occur between the loads. An analysis of the point of the first crack shows, that only $50 \%$ of all cracks occur in a distance less than $4 \mathrm{~cm}$ around the mid of the beam. At distances of less than $2 \mathrm{~cm}$ from mid-span, less than $25 \%$ of all cracks occur.

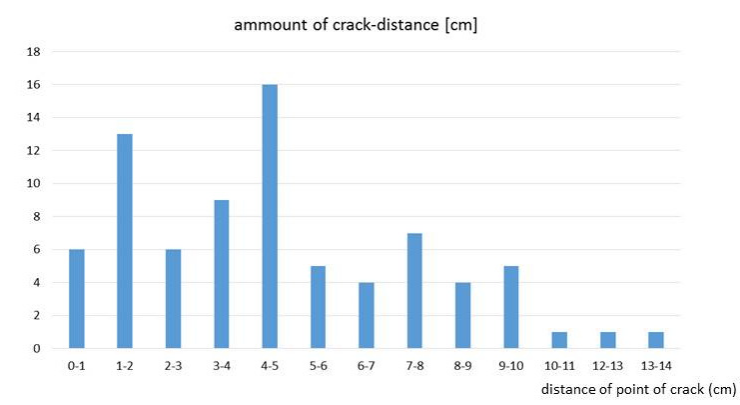

FiguRE 5. Distance of point of crack from mid-span

Applying the correction approach for the point of crack on several beams, the post-peak flexural strength values are affected as well. The larger the distance of the crack from mid-span the higher the correction, strain softening assumed. Most of the beams have shown force-deflection curves comparable to Fig. 4 As mentioned, these beams often show little strain hardening at low deflections. Because the correction at $\delta=0.5 \mathrm{~mm}$ is small, the post-peak flexural strength values are unaffected for a large number of beams. Due to the slight strain hardening, the post-peak flexural strength values decrease for a number of beams. At larger deflections of $\delta=3.5 \mathrm{~mm}$ the correction is higher, because of the higher deflection in combination with the strain softening. The mean increase ranges at about $0.15 \mathrm{~N} \cdot \mathrm{mm}^{-2}$, which is half a performance class.

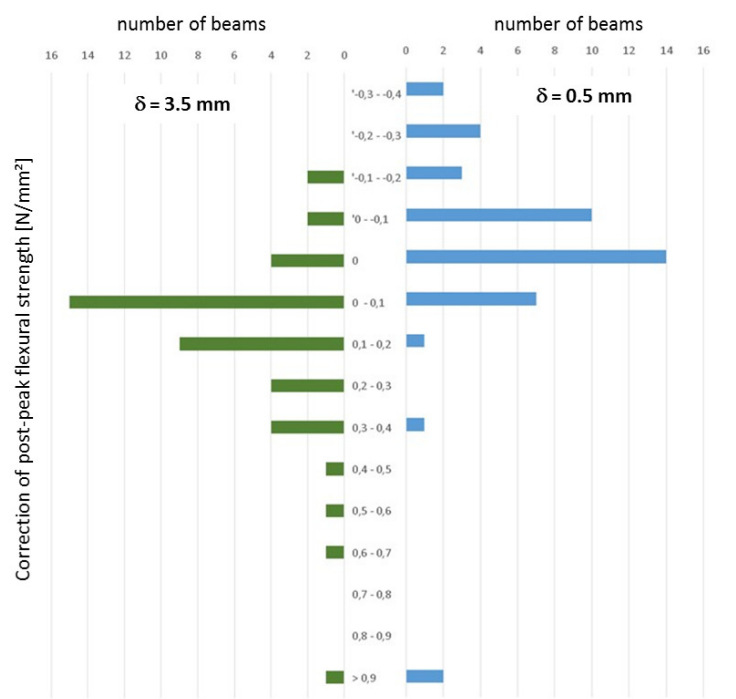

FiguRE 6. Effect of correction of post-peak flexural strength due to random cracking of beams tested according to DAfStb Guideline "Stahlfaserbeton"

\section{Conclusions}

For the determination of performance of SFRC, different testing and evaluation approaches are used in Germany and in Europe. From a point of view of fracture mechanics, the German approach is incorrect, due to a random occurrence of the cracks predominantly in the mid-third. This leads to a systematic underestimation of the deflection in the cracked cross-section. Therefore, it is essential to take the point of the first crack into account, leading to a stretching of the forcedeflection curve. Two different modes of behavior can occur. For strain hardening, which is often found at low deflections and at higher fiber contents, the postpeak flexural strength can decrease, and for strain softening behavior, usually found for concrete having lower fiber contents as well as at higher deflections, the post peak flexural strength increases.

Taking the point of crack into account leads to an increase of about half a performance class on an average. In further steps, the results should directly be related to results from tests according to EN 14651. Additionally, the different geometries caused by the notches have to be taken into account.

\section{REFERENCES}

[1] DIN EN 14651: Prüfverfahren für Beton mit metallischen Fasern - Bestimmung der Biegezuggfestigkeit (Proportionalitätsgrenze, Residuelle Biegezugfestigkeit) 2004.

[2] Deutscher Ausschuss für Stahlbeton (DAfStb): DAfStb-Richtlinie Stahlfaserbeton 2012.

[3] Fédération international du béton (fib): Modelcode for concrete structures 2010.

[4] B. Barr, et al. Round-robin analysis of the RILEM TC 162-TDF beam-bending test: Part 2 - application of delta from the CMOD response. Materials and Structures 36(263):621-630, 2003. DOI:10.1617/13954. 